\title{
Inventions of scientists, engineers and specialists from different countries in the area of nanotechnologies. Part IV
}

\author{
L.A. Ivanov ${ }^{*}$ (iD, L.D. Xu ${ }^{2}$ (D) Zh.V. Pisarenko ${ }^{3}$ (D), C.T. Nguyen ${ }^{4}$ (D) S.R. Muminova ${ }^{5}$ (iD \\ ${ }^{1}$ Russian Academy of Engineering, Moscow, Russia \\ ${ }^{2}$ Old Dominion University, Norfolk, Virginia, USA \\ ${ }^{3}$ Saint-Petersburg State University, Saint-Petersburg, Russia \\ ${ }^{4}$ Vietnam Academy of Social Sciences, Hanoi, Vietnam \\ ${ }^{5}$ Center for New Technologies "Nanostroitel'stvo", Korolev, Moscow region, Russia \\ *Corresponding author: e-mail: L.a.ivanov@mail.ru
}

\begin{abstract}
Introduction. Advanced technologies impress people's imagination demonstrating the latest achievements (materials, methods, systems, technologies, devices etc.) that dramatically change the world. This, first of all, concerns nanotechnological inventions designed by scientists, engineers and specialists from different countries. Main part. The paper briefly reviews inventions made by scientists, engineers and specialists from different countries: Russia, USA, China, Belarus, Great Britain, Vietnam, Denmark, the Kyrgyz Republic. The application of the results of scientists', engineers' and specialists' investigations, including inventions in the area of nanotechnology and nanomaterials allow achieving significant efficiency in construction, house and communal service, related sectors of economy. For example, the invention "A method to modify concrete with complex additive which includes hydrothermal nanoparticles $\mathrm{SiO}_{2}$ and multi-layer carbon nanotubes" refers to methods of modifying concrete by introducing combination of nanoparticles with high specific surface into concrete mixture and can be used in production of precast and monolithic parts and structures of buildings and facilities of different purpose. This method of nanomodifying concrete makes it possible to achieve increased mechanical characteristics of concrete: compressive strength (25-77\% at the age of 28 days) and bending strength, resistance to damage, Young's mod of elasticity and shearing modulus, density (up to 10\%), accelerated hardening at the early age and rate of strength development, decreased water absorbtion ability and improved indicators of porous structure (pore size and pore differential size uniformity), decreased total capillary porosity, increased frost resistance. The specialists can also be interested in the following nanotechnological inventions: a method to obtain polycrystalline diamond films; phase change materials for building construction: an overview of nano-/microencapsulation, solar collector of transpiration type; a method to obtain composition for antimicrobic coating on the basis of silver sulphide associates with molecules of methylene blue; broadband electromagnetic absorbing coating; a method to produce dry building mixtures; self-organizing nanostructures and separation membrane including aquaporin water channels and the methods to produce and use them; a method to obtain nanocrystalline titanium dioxide with anatase structure, etc. Conclusion. One of the most challenging tasks the economy of every country face is to increase industrial competitiveness through technological upgrade. From the side of the state and companies the principal object to control in this process are the people and enterprises dealing with introduction of inventions and new technologies.
\end{abstract}

KEYWORDS: nanotechnologies in construction, nanomodifying of concrete, nanodiamond powders, self-organizing nanostructures, silver nanoparticles, nanocomposite.

ACKNOWLEDGMENTS: This paper has been carried out in the framework of the RFFI 21-510-92001 project "Empowerment of Russia and Vietnam on the World Markets from the Risks Perspective of Ecosystem Financial Conglomerates Development and Transition of National Economies to Industry 4.0".

FOR CITATION: Ivanov L.A., Xu L.D., Pisarenko Zh.V., Nguyen C.T., Muminova S.R. Inventions of scientists, engineers and specialists from different countries in the area of nanotechnologies. Part IV. Nanotechnologies in Construction. 2021; 13(4): 242-251. Available from: doi: 10.15828/2075-8545-2021-13-4-242-251.

(c) Ivanov L.A., Xu L.D., Pisarenko Zh.V., Nguyen C.T., Muminova S.R., 2021 


\section{INTRODUCTION}

$\mathrm{A}$ dvanced technologies impress people's imagination demonstrating the latest achievements (materials, methods, systems, technologies, devices etc.) that dramatically change the world. This, first of all, concerns nanotechnological inventions designed by scientists, engineers and specialists from different countries.

\section{MAIN PART}

A method to modify concrete with complex additive which includes hydrothermal nanoparticles $\mathrm{SiO}_{2}$ and multilayer carbon nanotubes (RU 2750497 C1)

The invention refers to methods of modifying concrete by introducing combination of nanoparticles with high specific surface into concrete mixture and can be used in production of precast and monolithic parts and structures of buildings and facilities of different purpose [1].

Raw mixture for production of precast and monolithic parts and structures contains Portland cement, sand, broken natural stone, complex additive and water. Complex additive is polycarboxylate super plasticizer, multi-layer carbon nanotubes (MLCN) and hydrothermal nanosilica in the following component ratio, mas.\%: Portland cement 14-16; sand 38-40; broken natural stone 41-43; complex additive (respect to cement) 0.8 ; super plasticizer 0.32-0.4; MLCN 0.00004-0.05; hydrothermal nanoparticles $\mathrm{SiO}_{2}$ 0.000003-0.01; water $(\mathrm{W} / \mathrm{C}=0.15-0.5)$ the rest.

The aim of the invention is to improve characteristics of Portland cement concretes and structure of hydrated calcium silicate gel by using complex additive which contains hydrothermal nanoparticles $\mathrm{SiO}_{2}$ and carbon nanoparticles. This method of nanomodifying concrete makes it possible to achieve increased mechanical characteristics of concrete: compressive strength $(25-77 \%$ at the age of 28 days) and bending strength, resistance to damage, Young's mod of elasticity and shearing modulus, density (up to 10\%), accelerated hardening at the early age and rate of strength development, decreased water absorbtion ability and improved indicators of porous structure (pore size and pore differential size uniformity), decreased total capillary porosity, increased frost resistance.

This method allows improving structure of hydrated calcium silicate gel $\mathrm{CSH}$ in cement composite materials due to high specific area of surface and specific surface energy of nanoparticles $\mathrm{SiO}_{2}$ and carbon nanoparticles. The surface of nanoparticles acts as additional centers of crystallization of hydrated calcium silicate particles and polycondensation of silicon-oxygen tetrahedron, that favours increased rate of alite hydration and formation of CSH gel, reduced average sizes and increased volume density of particle packing and mechanical characteristics in phases CSH gel, increased structural order in phases of $\mathrm{CSH}$ gel and in hydrated calcium silicate particles.

\section{A method to obtain polycrystalline diamond films (RU 2750234 C1)}

The invention refers to the area of obtaining polycrystalline diamond films which are used in manufacture of thermal conduction module, ionizing-radiation detectors, infrared windows, strengthened and wear-resistant coatings on the details and cutting tools.

Polycristalline diamond films consist of diamond crystallites, which sizes, ratio of crystalline and amorphous phases strongly affect physical properties of such films. It was determined that reduced crystallite sizes and ratio of diamond and amorphous phases in polycrystalline diamond films makes it possible to significantly roughness of growth surface, that leads to changes in electric, optical and emission characteristics of films. As a rule, the start of growth of polycrystalline diamond films (diamond coatings) is followed by the period, during which diamond seeds are formed on the base. These seeds act as the nucleation centers of diamond phase of the film. Nanodiamond powders are used as diamond seeds. Higher and more even density of the diamond seeds with minimum dimensional dispersion on the base surface allows reducing sizes of diamond film crystallites and obtaining solid ultrathin diamond films with smooth surfaces [2].

The method is performed in the following way. To apply nanodiamond powder on silica base, one needs, at first, to prepare suspension from nanodiamond powder and liquid and then to impact on suspension with ultrasonic vibrations which power is $500-1000 \mathrm{Wt}$. After that power of ultrasonic vibrations is reduced to $250-350 \mathrm{Wt}$ and silica base is put into the suspension, the base is processed for the time during which nanodiamond particles are precipitated, introducing into base surface. "Seeded" base is taken from suspension, it is washed in deionized water and dried. Base surface is examined with electronic microscope to determine quality of seeding. Then a graphene layer which contains 3-10 monolayers of graphene is precipitated on the base nanodiamond powder. Then the base is placed into reactor to precipitate polycrystalline diamond layer. Material of the base does not depend on the method used to apply polycrystalline diamond films, the base can be made of silica, molibdenous and other materials but it is silica that is preferable material of the base.

Liquid phase is a suspension of nanodiamond powders in liquid. Acetone, isopropyl alcohol, ethanol, water can be used as liquid. Concentration of diamond powders in suspension must provide necessary quantity of diamond phase to obtain "seeding" of the base with proper density and to provide efficient disaggregation of nanodiamond powders in suspension. It is preferably to use nanodia- 
mond powders with size 4-10 nm for "seeding" the base, as they are optimal for obtaining high density of "seeding" and film with smooth surface.

Phase change materials for building construction: An overview of nano-/microencapsulation

Buildings contribute to $40 \%$ of total global energy consumption, responsible for $38 \%$ of greenhouse gas emissions. In the last decade, advances in thermal energy storage (TES) techniques using phase change material (PCM) have gained much attention among researchers, mainly to reduce energy consumption and promote renewable energy sources such as solar energy.

Phase change materials (PCMs) are a group of functional materials that support the same purpose as a function of temperature with the intrinsic capability of absorbing, storing, and releasing thermal energy in the form of latent heat known as enthalpy of fusion during phase transition cycles at their operating temperatures under isothermal conditions. PCM technology is one of the most promising technologies available for developing high-performance and energy-efficient buildings and, therefore, considered one of the most effective and ongoing fields of research. The main limitation of PCM is its leakage problem which limits its potential use in building construction and other applications such as TES and textiles, which can be overcome by employing nano-/ micro-encapsulation technologies [3].

This paper comprehensively overviews the nano-/ micro-encapsulation technologies, which are mainly classified into three categories, including physical, physiochemical, and chemical methods, and the properties of microcapsules prepared. Among all encapsulation technologies available, the chemical method is commonly used since it offers the best technological approach in terms of encapsulation efficiency and better structural integrity of core material. There is a need to develop a method for synthesizing nano-encapsulated PCMs to achieve enhanced structural stability and better fracture resistance, and, thus, longer service life. The accumulated database of properties/performance of PCMs and synthesized nano-/micro-capsules from various techniques presented in the paper should serve as the most useful information for the production of nano-/micro-capsules with desirable characteristics for building construction application and further innovation of PCM technology.

It will be beneficial to develop and apply nanoencapsulation techniques to synthesize nanocapsules, as they have several desirable characteristics, including better loading capacity and encapsulation efficiency, improved structural stability, and fracture resistance when compared with microcapsules resulting from microencapsulation. To promote the sustainability of the encapsulation technology, it is necessary to utilize biopolymers such as cellulose/nanocellulose as shell materials because such polymers are environmentally friendly and are available abundantly.

\section{Solar collector of transpiration type (RU 2749242 C2)}

Building structures are being improved, that often means better air tightness. Therefore it is of great importance to design such air-ventilation systems that could provide constant supply of fresh air into the building. If supplying fresh air is colder than bleeding warm air, the temperature inside the building can decrease. That may require building heating. Solar collectors of transpiration type can be used for pre-heating of the air supplied into the building, that will allow reducing necessity in heating by means of standard heating systems and providing cost reduction. Moreover, if the external energy is obtained from fossil energy source or nuclear sources, that provides considerable ecological benefits and decrease usage of scare sources.

The invention refers to solar collector of transpiration type that contains absorbing panel which base is made of stainless steel, surface layer made from chrome oxide is on the front surface of the base and a great number of through holes formed in the base and surface layer, and the thickness of surface layer is at least 70 nanometers and acts as external surface of solar collector of transpiration type [4]. The application also describes a building which comprises this collector installed on the roof or wall in such a way that the surface layer forms external surface of the building and a method to produce solar collector according to which the plate is made of stainless steel containing initial layer of chrome oxide on the front surface and then chemical and electrochemical growing of initial layer of chrome oxide on the front surface to form overgrown layer of chrome oxide, after that many through holes are made in the plate and the plate in the form of absorbing panel of solar collector of transpiration type is formed. Overgrown layer of chrome oxide becomes external surface of solar collector of transpiration type. One should note, the stage of chemical and electrochemical growing of initial layer of chrome oxide is performed prior or after the stage of forming a number of through holes. The invention could decrease radiant heating losses in the atmosphere, provide protection from ultraviolet light to prevent discolourment and damages in the coating, prolong service lifetime.

Fig. shows an example of solar collector of transpiration type 100 . Solar collector 100 of transpiration type is located on the external side 102 of the building and contains absorbing panel 108 (a panel with absorbing collector), installed on the wall 106 of the building by means of holderbats (not shown). The absorbing panel 108 contains a number of through holes 110 (punch holes). The absorbing panel 108 is at the distance from 


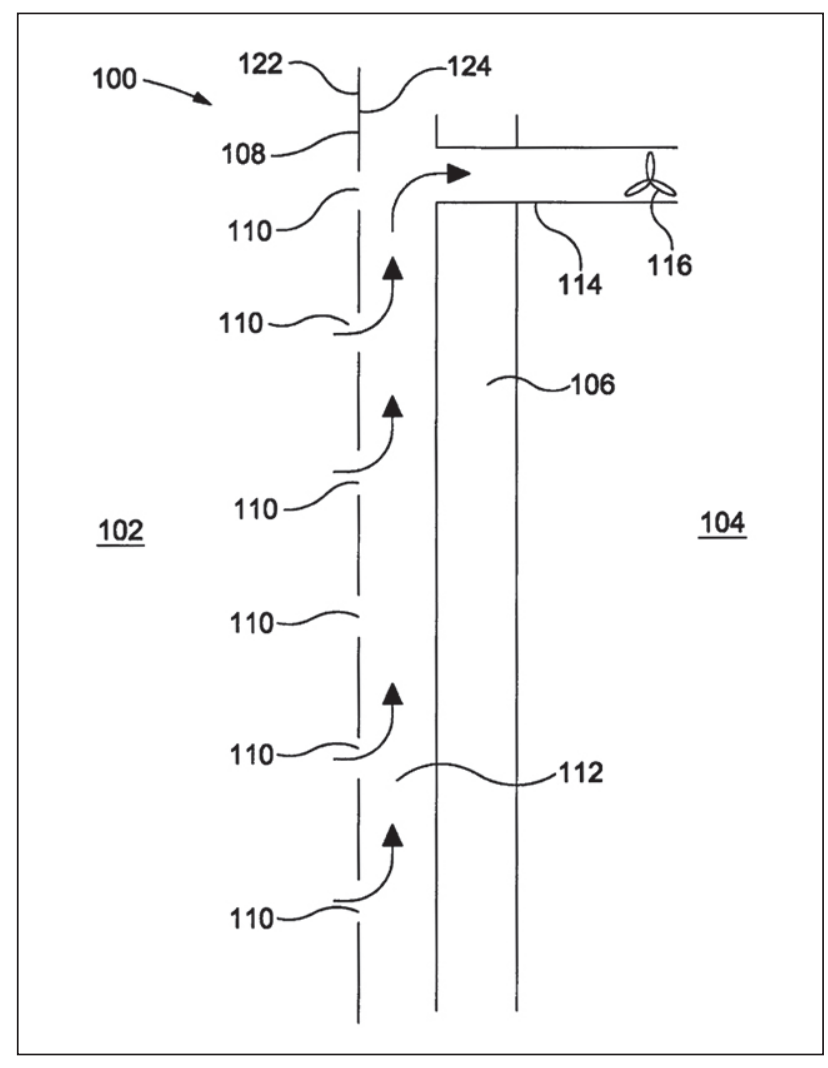

Fig. An example of solar collector of transpiration type

the wall 106, there is air space 112 between the absorbing panel 108 and the wall 106. The air space 112 is connected to fresh air duct 114 of the ventilation system. The fresh air duct 114 is used to supply fresh air into inner space 104 of the building. When operating, absorbing panel 108 absorbs solar radiance, that heats material of the absorbing panel 108. Bound layer which is adjacent to external (front) surface 122 of the absorbing panel 108, is heated by the absorbing plate 108 and is drawn through holes 110 in the air space 112 and then is drawn from space 112 into air outlet 114 by air fan 116 . The arrows show air flow through the absorbing panel 108 and ventilation system on the Fig.

A method to obtain composition for antimicrobic coating on the basis of silver sulphide associates with molecules of methylene blue (RU 2750232 C1)

The invention refers to the area of antimicrobic compositions, specifically to the area of obtaining compositions with silver sulphide nanocrystals. Such compositions are added to lacquer materials and are used to disinfect different surfaces.

It is well-known that silver ions and some other metal ions have an ability to inactivate viruses of some flu strains, entero- and adenoviruses. They possess considerable therapeutic effect in medical treatment of some virus human and animal deceases, especially when col- loid silver is used, respect to standard therapy. Therefore, the promising approach to creation of new generation of antimicrobic compositions is the use of colloid metal nanoparticles and semiconductive nanocrystals as well as hybrid associates on the basis of them.

The scope of the invention is to develop a method to produce composition for antimicrobic coating on the basis of silver sulphide associates with molecules of methylene blue. Hydrophylic property of the composition obtained as a result of this method makes it possible to use it to treat room surfaces and also to provide compatibility with emulsion paints to achieve antimicrobic effect. Created compositions are not volatile, do not possess odor, are not toxic and keep effect for a long time [5].

The technical result of the invention is achieved due to the following stages of the method used to obtain composition for antimicrobic coating on the basis of silver sulphide associates with molecules of methylene blue: synthesis of nanocrystals $\mathrm{Ag} 2 \mathrm{~S}$ by consolidating thioglycolic acid and silver nitrate under temperature $30^{\circ} \mathrm{C}$ and constant mixing with further drop titration with aqueous solution $\mathrm{NaOH}$, and then addition of sodium sulphide solution with further mixing, adding acetone into solution in ratio $1: 1$; centrifugalization with further decanting of water, addition of solvent and solution of methylene blue in $96 \%$ ethanol to sediments. According to the invention, the synthesis is performed by adding $0.0135-0.0154 \mathrm{M}$ of silver nitrate aqueous solution to $0.027-0.03 \mathrm{M}$ of thioglycolic acid aqueous solution under constant mixing with the rate 300-600 rpm and molar ratio 2:1 respectively. Drop titration is performed with $0.1 \mathrm{M}$ of aqueous solution $\mathrm{NaOH}$ up to $\mathrm{pH}=9$, and them adding $0.02-0.023 \mathrm{M}$ of aqueous solution of sodium sulfide (temperature is from 15 to $25^{\circ} \mathrm{C}$ ) under volume ratio thioglycolic acid aqueous solution : silver nitrate aqueous solution : sodium sulphide solution $-2: 2: 1$ respectively. All that is mixed for at least 20 minutes, precipitated and is separated from water soluble resultants by centrifuging at rate $5000 \mathrm{rpm}$ for 30 minutes. Then $50 \%$ aqueous ethanolic solution taken in the volume which is equal to the sum of volumes of mixed silver nitrate solution, thioglycolic acid solution and sodium sulphide solution is added to the obtained sediment; solution of methylene blue in $96 \%$ ethanol is added.

\section{Broadband electromagnetic absorbing coating (RU 2750215 C1)}

The invention refers to electromagnetic absorbing coatings used to absorb electromagnetic radiation in ground, aviation, space and marine technical devices to reduce their radar visibility as well as to absorb electromagnetic radiation in shadowing devices, in absorbing clothings and frameworks, in anechoic measurement chambers and protective facilities for citizens from non- 
ionizing radiation [6]. Known electromagnetic absorbing coatings are based on ability to absorb incoming radiation by fine elements: clusters of ferromagnetic particles, ferrites and hydrogenated carbon.

The task of applied invention is to broaden absorption frequency range of the coating, specifically to raise maximum absorption frequency up to $\approx 700 \mathrm{GHz}$ and to decrease minimum absorption frequency to $\approx 10 \mathrm{MHz}$.

The imposed task is solved by applying nanoparticles of copper-nickel alloy which composition includes $25-50$ mas. \% Cu and the rest is $\mathrm{Ni}$ in absorbing film. At this, raised maximum frequency of absorption band up to $\approx 700 \mathrm{GHz}$ is due to the nanoparticle size which is equal or less than thickness of skin-layer at maximum absorbed frequency ( $\approx 400 \mathrm{~nm}$ at frequency $700 \mathrm{GHz}$ ). That provides broad band of electromagnetic radiation absorption frequency because radiation of all frequencies, equal of less than maximum one, penetrates into volume of nanoparticle and is absorbed in it interacting with all Fermi electrons of nanoparticle. This is a result of the fact that the thickness of skin-layer at the frequencies, less than maximum one, is more than a thickness of skinlayer at maximum frequency. Reduction of minimum frequency of absorption band to $\approx 10 \mathrm{MHz}$ is provided by applying technology of absorbing of electromagnetic field quantum with participation of dominating dilatational quantum, i.e. quantum from the area of full width at the mid of maximum (FWMM area) frequency distribution of dilatational quantum, in nanoparticles. In this technology Fermi electron is excited when it absorbs simultaneously radiation quantum and dominating dilatational quantum. And it relaxes, when excites secondary dilatational quantum from FWMM area. Due to participation of dominating quantums in absorption, the intensity of electromagnetic radiation absorption is raised. At this, it is wavelength of dilatational quantum from FWMM area $(\sim 0.5 \mathrm{~nm})$ which is much less than the size of nanoparticle $(\leqslant 400 \mathrm{~nm})$ that provides participation of dilatational quantums.

\section{Self-organizing nanostructures and separation membrane including aquaporin water channels and the methods to produce and use them (RU 2749848 C2)}

The invention refers to self-organizing nanostructures formed by transmembrane proteins, such as aquaporin water channel (AQP) and polyalkyleneimines (PAI) and to filtration membranes which comprise these nanostructures [7]. This invention additionally refers to the methods used to obtain nanostructures and separation membranes, such as hollow fibers and hollow fiber module, to their application.

In general, this invention refers to application of polyalkyleneimines (PAI), such as polyethyeneimine (PEI), in formation of self-organizing nanostructures with trans- membrane proteins or specified types of integral membrane proteins (proteins that form pores), such as aquaporin water channels. Nanostructures of PAI-protein can be used later in obtaining separation membranes in which transmembrane proteins are immobilized and active, for example, to provide transfer of water molecules through membrane. For example, to obtain separation membranes with transmembrane proteins self-organizing nanostructures can be suspended in aqueous liquid composition that may be involved in reaction of interphase polymerization on semipermeable base with formation of thin film composite active layer of membrane or self-organizing nanostructures can be included in filtration membrane formed by layer-by-layer method or other types of filtration membrane with active selective layer. Without regard to any certain theory, self-organizing nanostructures are considered to emerge due to electrostatic interaction between positive nitrogen atoms which are in polyalkyleneimine molecules and amino acid residues in transmembrane protein which are negative charged under conditions $(\mathrm{pH}$, $\mathrm{pK}$, etc.), used for formation of nanostructures and/or membrane containing these nanostructures.

Thus, the described invention offers separation membranes, such as filtration membranes or TFC membranes, possessing $\mathrm{AQP}$, involved in active layer to enhance water transport. In active layer AQP are immobilized in selforganizing PAI nanostructures, such as self-organizing PEI nanostructures. The invention also offers liquid compositions containing nanostructures on the basis of PAIprotein which can be imployed in active layer of different separation membranes (including filtration membranes), such as nanofiltration membranes, forward osmosis membranes and reversed osmosis membranes.

A method to obtain alumina ceramic material, modified with silver nanoparticles (RU 2749340 C1)

The invention refers to the technology for obtaining ceramics containing silver nanoparticles which can be used as filters to decontaminate water from harmful bacteria [8]. It is known that different materials, modified with silver, for example, composites, ceramics, steel, porcelain, faience ware, possess antimicrobic characteristics. In particularly, composites on the basis of ultrahigh-molecule weight polyethylene (UHMWPE) modified with silver are known to possess antibacterial properties. In recent years, it is nanostructured silver that has been of great interest.

To create economic and industrial process of producing efficient ceramics which could be used as filters to decontaminate water from harmful bacteria, a method to obtain alumina ceramic material, modified with silver nanoparticles is proposed. There are two stages in this method: preliminary treatment of initial alumina ceramic material with $20 \%$ porosity and further impregnation of it. Preliminary treatment of initial alumina ceramic material 
consists of: exposure of initial alumina ceramic material to ultrasound, preferable value is $30 \mathrm{kHz}$, for $15-30 \mathrm{~min}$; washing it with distilled water and dipping it into concentrated nitric acid for 2-4 hours, then rewashing with distilled water and drying under temperature $140-160^{\circ} \mathrm{C}$. Impregnation stage of ceramic material treated with nanosilver is conducted by dipping the treated ceramic material in solution containing 0.004 mole of silver methane sulfonate or silver trifluoroacetate in $100 \mathrm{ml}$ of ethylene glycol. Then it is kept being shaked and mixed till even distribution of solution on the surface of the material and after that a solution, containing 0.002 mole of ascorbic acid in $100 \mathrm{ml}$ of ethylene glycol, is added to it. Than impregnated material is kept being shaked and mixed under room temperature for 1-2 hours, obtained ceramic material is washed with distilled water and is dried under $70-90^{\circ} \mathrm{C}$.

\section{A method of synthesis of nanocomposite $\mathrm{Mn}-\mathrm{O}-\mathrm{C}$ (RU 2749814 C1)}

The method refers to nanotechnology: plasma arc technology of synthesizing nanocomposite particles of manganese oxide with carbon coating [9]. The invention can be also used as a material for electrodes of supercondensers (SC). Supercondensers are the most promising energy sources as they possess high output and high power capacity at the same time, that differs from traditional accumulator batteries and condensers. High power capacity of supercondensers is due to materials of electrodes. Materials of electrodes in SC are those that combine high specific capacity and long service life, for example, carbon nanomaterials, transition metals and conductive polymers Max-phase and MAXene.

The most promising oxide of transition metal SC electrodes is considered to be manganese oxide ( $\mathrm{MnOx}$ ) due to its high specific capacity (1370 F/g), low cost, wide availability and ecological safety. However, $\mathrm{MnOx}$ possess low stability in long cycles, that is caused by charge accumulation mechanism and electrolyte ion doping. When manganese transits from one oxidation state in another, the system becomes incompensated, that results in doping/deposition of additional ions from electrolyte solution. During this process interlayer space enlarges/ reduces, that finally results in fast destroying of crystal structure and material damage. Thus, MnOx oxides are stable only in the course of $1000-3000$ cycles. The efficient method to increase stability of $\mathrm{MnOx}$ is to create composites with amorphous carbon or carbon nanostructures. In such composites carbon acts as a matrix which retain and stabilize particles of $\mathrm{MnOx}$ during electrolyte ion doping and metals or their compounds - as active elements. Moreover, carbon is needed to increase electrical conductivity of material, to decrease losses at the interface between active material and collector.
The task of the invention is to create easy-to-use and economic method of synthesizing nanocomposite $\mathrm{Mn}-$ $\mathrm{O}-\mathrm{C}$ with controlled composition of $\mathrm{MnOx}$ nanoparticles and degree of carbon matrix graphitization, with high cycle stability and high electrochemical capacity to be used as a material of electrodes in SC. The imposed task is solved by combining traditional methods, in particular, plasma arc synthesis of composite metal-carbon material and annealing of synthesized material in oxygen-containing medium under atmosphere pressure. As a result, obtained material possesses improved characteristics, high cycle stability and high electrochemical capacity, and it can be used as a material of electrodes in SC.

A method to obtain nanocrystalline titanium dioxide with anatase structure (RU 2749736 C1)

The invention refers to Material Science and nanotechnologies, in particular, to obtaining titanium dioxide which can be used in hydrogen power industry and water treatment. The technical result of the invention is creation of the method to obtain nanocrystalline titanium dioxide with anatase structure, in composition of the product with low content of impurity phase [10].

The method to obtain nanocrystalline titanium dioxide with anatase structure is performed in the following way: generating of titanium electrical discharge plasma in the chamber, preliminary vacuumized and filled with oxygen-containing gas mixture under normal atmosphere pressure and room temperature by means of coaxial magnetoplasma accelerator with titanium core and with central electrode consisting of titanium tip and steel shank, with electrically fusible link placed between titanium tip and steel shank, and condenser capacity is $14.4 \mathrm{mF}$.

According to the invention, titanium electrical discharge plasma is generated with coaxial magnetoplasma accelerator with electrically fusible geoline link which mass is from 0.10 to $0.25 \mathrm{~g}$., spraying plasma in the first chamber filled with gas mixture of argon and oxygen in ratio of partial pressure Ar: $\mathrm{O}_{2}$ 1:4 and charge voltage of capacitors battery is $2.8 \mathrm{kV}$, nanocrystalline part of the synthesized product is moved to the second prevaccumized chamber, opening overflow valve between chambers in 10 seconds after generation of electrical discharge plasma. After that titanium dioxide with anatase structure is collected from the internal walls of the second chamber.

When capacity energy accumulator between titanium tip of central electrode and titanium core of the accelerator is discharged, arc discharge initiation takes place, as a result of that electrically fusible geoline link gets plasma state. Electronic erosion development of titanium-containing precursor from inner surface of cylindrical electricity conductive titanium core takes place in the process of burning of arc charge. Plasma flow is accelerated up 
to hypersonic speed and eroded titanium participates in plasmachemical reaction with oxygen of the first chamber, that provides formation of nanocrystaline titanium dioxide with anatase structure. Separation of synthesized nanocrystalline anatase from coarse rutile is provided by opening overflow valve and collecting product from the second chamber. The advantage of this method is the use of hydrogen-containing electrically fusible link since geoline, apart of mineral oil, contains hard saturated hydrocarbons. Geoline link is heated, is melted and hydrogen from it is relieved, favouring speeded flow of plasma. This invention allowed obtaining products in which content of nanocrystalline anatase is from 83.2 to 85.7 mas. $\%$ and average size of particles is up to $100 \mathrm{~nm}$.

\section{Epoxy composition of cold hardening (RU 2749379 C2)}

The invention refers to creation of epoxy compositions of cold hardening used as a base for glues, joint sealers and compounds for encapsulation and repairing items of various materials. Epoxy compositions possess high strength and deformation characteristics during operation process under wide range of temperature, including the conditions in Arctic and Extreme North. The task to gain improved deformation-strength properties is of great importance today.

The essence of the invention is explained by the example [11]. Epoxyurethane oligomer CKY-1400-3A is synthesized in two stages: at the first stage a reaction between oligotetramethyleneoxidediol with molecule mass 1400 (trade mark polyfurite 1400) and 2.4-toluene diisocyanate, taken twice more respect to stoichiometry, runs. The reaction that runs under $80^{\circ} \mathrm{C}$ in hermetically sealed reactor equipped with mechanical mixer and heating jacket for 5-6 hours with mixing results in oligoesterurethanediisocyanate (urethane forpolymer with functional isocyanate groups) with content of free isocyanate groups $4-4.7-4.8 \%$. At the second stage obtained product interacts, while mixing, with glycidol taken twice more respect to stoichiometry in the mentioned reactor under $80^{\circ} \mathrm{C}$ for 5-6 hours. The final product oligomer CKY-1400-3A is a dense viscous transparent liquid and its content of free epoxy groups is $4.2-4.85 \%$.

At the first stage, achievement of constant content of isocyanate groups in synthesis is controlled by reversed titration method according to the regulations TU-11303413-89 (ТУ-113-03413-89), and at the second stage content of free epoxy groups is determined by reversed titration method according to GOST 12497-78 (ГОСТ 12497-78).

Preparation of epoxy composition is conducted in the mentioned reactor gradually loading and continual mixing of components: 100 pts.wt. of epoxy diane resin ЭД-20 (GOST 10587-90), 4 pts.wt. of plasticizer, oligomer СКУ1400-3A. In the mixture of components, loaded into re- actor, 0.6 pts.wt. of nanomaterial is added, after that the mixture is dispersed by ultrasonic impact with the plant Bandelin Sonopuls HD-3200 (ISO 9001/12.2000) for 2 min under frequency $22 \mathrm{kHz}$.

A method to obtain composite sorbent to educe heavy metal ions from aquaeius solutions (RU 2750034 C1)

The invention refers to chemical industry, in particular, to the methods of obtaining composite sorbents, containing chitosan, used to educe heavy metal ions by sorption from various solutions formed as a result of different technological processes and can be applied in improving membrane and sorption technologies, in water treatment, in development of technologies aimed at utilization of heavy metal ions from aqueous solutions and waste water of different nature [12].

The technical result of the invention is reduced time of chitosan expanding in $1 \%$ solution of acetic acid and increased sorption capacity of sorbent respect to heavy metal ions. The result is achieved due to the following stages: mixing of chitosan solution in $1 \%$ acetic acid with disperse of reinforcing material in distilled water, intensive mixing and gradual adding epichlorhydrin as a crosslinking agent. Crosslinking agent is mixed until its total inclusion into reaction mixture. Then prepared mixture is drop-by-drop introduced into aqueous solution of sodium tripolyphosphate with concentration $0.05 \mathrm{M}$ under mixing. Emerged microspheres are cured under microwave radiation which power is $300 \mathrm{Wt}$ and frequency is $2.45 \mathrm{GHz}$, temperature $25-40^{\circ} \mathrm{C}$ for $15-25 \mathrm{~min}$ and then they are separated from dispersed medium and thoroughly washed in distilled water from unconverted sodium tripolyphosphate. Carbon nanotubes "Taunit-M" are used as reinforcing dispersed material, and gelatin water is additionally introduced into chitosan solution, mass ratio "gelatin : chitosan" is 1:5 $1: 3$ and mass ratio between reinforcing dispersed material and mixture of chitosan and gelatin is 1:10-1:2. Mixing of chitosan solution in $1 \%$ acetic acid is carried out for 20-MM30 min with further ultrasonic treatment which lasts for 10-20 min and expansion in rest without mixing runs for $30-40 \mathrm{~min}$.

The specialists can also be interested in the following inventions related to nanotechnologies:

- Wear-resistant and yellowing-resistant decorative material and preparation method thereof [13].

- The composition of paint or coating, which allows to suppress microbial corrosion in metal surfaces [14].

- Graphene modified with nitrogen atoms and a method to produce it [15].

- A method to grow wire-type silica crystals [16].

- Raw mixture to obtain coarse semi-finished product of superhard composite material [17]. 
- A method to obtain multilayer wear-resistant diamond like coatings [18].

- A technical solution for water purification based on the use of a contact filter containing bioactive carbon particles. Allows more careful removal of pollutants, can efficiently process contaminated surface water, suitable for use in all industries in Vietnam [19].

- A method to form nanostructured composite materials [20].

- A method to obtain sintered products of unaxially pressed electroerosion nanodispersed powders of lead bronze [21].

- Electrochemical method to obtain nanowhiskers of copper oxide [22].

- Heat-insulating material based on air gel with the possibility of introducing nanomaterials into the final product [23].

- The stage of chemical modification of graphene functionalization, and its use - is described [24].

- A transparent glass-ceramics protecting from nearinfrared radiation [25].

- A method to obtain nanoparticles of copper oxide (II) [26].

- Metal pigments with anticorrosion coatings on the basis of aluminum and/or its alloys [27].
- A method to produce dry construction mixtures [28].

- A method to obtain composite metal-dispersed coating [29].

- The utility model. A new eco-friendly wallboard is made of bamboo wood flour, characterized in that the body of the wall shield is made on the basis of polymer nanotechnology. It has the property of fire resistance, water resistance, protection against moths and corrosion, have a thermal insulation effect, improve the performance and comfort level of buildings [30].

- A method to obtain nanostructured material for anodes of metal-ion batteries [31].

\section{CONCLUSION}

One of the most challenging tasks the economy of every country face is to increase industrial competitiveness through technological upgrade. From the side of the state and companies the principal object to control in this process are the people and enterprises dealing with introduction of inventions and new technologies.

Therefore, we hope that the information published in this section will be in demand and useful for specialists.

\section{REFERENCES}

1. Potapov V.V., Polonina E.N., Leonovich S.N., Zhdanok S.A. A method to modify concrete with complex additive which includes hydrothermal nanoparticles $\mathrm{SiO}_{2}$ and multi-layer carbon nanotubes. RF Patent 2750497. 2021-06-28.

2. Polushin N.I., Maslov A.L., Laptev A.I. A method to obtain polycrystalline diamond films. RF Patent 2750234. 2021-06-24.

3. Sivanathan, A., Dou, Q., Wang, Y., Li, Y., Corker, J., Zhou, Y., \& Fan, M. (2020). Phase change materials for building construction: An overview of nano-/micro-encapsulation. Nanotechnology Reviews, 9(1), 896-921. https://www.degruyter.com/document/doi/10.1515/ntrev-2020-0067/html

4. Blauer E.D., Hall R. Solar collector of transpiration type. RF Patent 2749242. 2021-06-07.

5. Ovchinnikov O.V., Smirnov M.S., Perepelitsa A.S. et al. A method to obtain composition for antimicrobic coating on the basis of silver sulphide associates with molecules of methylene blue. RF Patent 2750232. 2021-06-24.

6. Moldosanov K.A., Lelevkin V.M Broadband electromagnetic absorbing coating. RF Patent 2750215. 2021-06-24.

7. Spulber M., Tshaskus K. Self-organizing nanostructures and separation membrane including aquaporin water channels and the methods to produce and use them. RF Patent 2749848. 2021-06-17.

8. Glushko V.N., Sadovskaya N.Yu., Blokhina L.I., Malozovskaya M.S. A method to obtain alumina ceramic material, modified with silver nanoparticles. RF Patent 2749340. 2021-06-08.

9. Smovzh D.V., Sakhapov S.Z., Yurchenkova A.A. et al. A method of synthesis of nanocomposite Mn-O-C. RF Patent 2749814. 2021-06-17.

10. Sivkov A.A., Vympina Yu.N., Nikitin D.S. et al. A method to obtain nanocrystalline titanium dioxide with anatase structure. RF Patent 2749736. 2021-06-16. 
11. Strelnikov V.N., Senichev B.Yu., Slobodinyuk A.I. et al. Epoxy composition of cold hardening. RF Patent 2749379. 2021-06-09.

12. Nikiforova T.E., Kozlov V.A. A method to obtain composite sorbent to educe heavy metal ions from aquaeius solutions. RF Patent 2750034. 2021-06-21.

13. Ivanov L.A., Xu L.D., Pisarenko Zh.V., Wang Q., Prokopiev P.S. Inventions of scientists, engineers and specialists from different countries in the area of nanotechnologies. Part II. Nanotechnologies in Construction. 2021; 13(2): 79-89. Available from: doi: 10.15828/2075-8545-2021-13-2-79-89.

14. González P., Ivon C., Raúl F., Ricardo H., Del Campo V. Nanostructured paint for reducing microbial corrosion. EP309423237 European Patent Office (EPO). Publication number: 3725740. Available from: https://patentscope.wipo.int/search/ru/detail.jsf?docId=EP309423237\&_cid=P10-KQZD4R-33894-1

15. Chesnokov V.V., Parmon V.N., Chichkan A.S. Graphene modified with nitrogen atoms and a method to produce it. RF Patent 2750709. 2021-07-01.

16. Svaikat N. A method to grow wire-type silica crystals. RF Patent 2750732. 2021-07-01.

17. Malchukov V.V., Metsker E.A., Andrianov M.A. Raw mixture to obtain coarse semi-finished product of superhard composite material, coarse semi-finished product of superhard composite material and a method to obtain it. RF Patent 2750448. 2021-06-28.

18. Ivanov L.A., Xu L.D., Bokova E.S., Ishkov A.D., Muminova S.R. Inventions of scientists, engineers and specialists from different countries in the area of nanotechnologies. Part I. Nanotechnologies in Construction. 2021; 13(1): 23-31. Available from: doi: 10.15828/2075-8545-2021-13-1-23-31.

19. Truong C. N. Bio-contact filtration tanks, water treatment systems and methods for treating contaminated water sources. VN1/070771. 2020. Available from: https://patentscope.wipo.int/search/ru/detail.jsf?docId=VN308555523

20. Klinov D.V. A method to form nanostructured composite materials. RF Patent 2749020. 2021-06-03.

21. Ageeva E.V., Ageev E.V., Pereverzev A.S. A method to obtain sintered products of unaxially pressed electroerosion nanodispersed powders of lead bronze. RF Patent 2748659. 2021-05-28.

22. Vakarin S.V., Semerikova O.L., Kosov A.V. et al Electrochemical method to obtain nanowhiskers of copper oxide. RF Patent 2747920. 2021.

23. Ivanov L.A., Ishkov A.D., Pisarenko Zh.V., Wang Q., Prokopiev P.S. Nanotechnologies: a review of inventions and utility models. Part IV. Nanotechnologies in Construction. 2020;12(5): 275-284. Available from: doi: 10.15828/2075-8545-2020-12-5-275-284.

24. Nguyen K., Nguyen P. Chemically Functionalized Graphene and its Applications. US Patent \& TradeMark Office. US284281968. United States. Publication Number 20200056081. 2020. Available from: https://patentscope. wipo.int/search/ru/detail.jsf?docId=US284281968

25. Deineka M.D., Col D., Patil M.D. A transparent glass-ceramics protecting from near-infrared radiation. RF Patent 2747856. 2021-05-17.

26. Zelenov V.I., Andriichenko E.O., Bovyka V.E. A method to obtain nanoparticles of copper oxide (II). RF Patent 2747435. 2021-05-05

27. Garshev A.V., Putlyaev V.I., Evdokimov P.V. et al. Metal pigments with anticorrosion coatings on the basis of aluminum and/or its alloys. RF Patent 2746989. 2021-04-23.

28. Ivanov L.A., Xu L.D., Bokova E.S., Ishkov A.D., Muminova S.R. Nanotechnologies: are view of inventions and utility models. Part V. Nanotechnologies in Construction. 2020; 12(6): 331-338. Available from: doi: 10.15828/20758545-2020-12-6-331-338.

29. Esaulov S.K., Esaulova Ts.V. A method to obtain composite metal-dispersed coating, dispersed system to precipitate composite metal-dispersed coating and a method to produce it. RF Patent 2746863. 2021-04-21.

30. Qiuyu C. Novel ecological wallboard of bamboo wood flour CN212926688U. Worldwide applications. 2020. Available from: https://patents.google.com/patent/CN212926688U/en?q=nanotechnology+\&after=priority:20200 $101 \&$ status $=$ GRANT\&page $=4$

31. Stolyarova S.G., Okotrub A.V., Bulusheva L.G. A method to obtain nanostructured material for anodes of metal-ion batteries. RF Patent 2751131. 2021-07-08 


\section{INFORMATION ABOUT THE AUTHORS}

Leonid A. Ivanov, Cand. Sci. (Eng.), Vice President of the Russian Academy of Engineering, Member of the International Journalist Federation; Moscow, Russia, ORCID: https://orcid.org/0000-0001-9513-8712, e-mail: L.a.ivanov@mail.ru

Li D. Xu, Ph.D., Prof., Old Dominion University, of Information Technologies \& Decision Sciences Department; Institute of Electrical and Electronics Engineers (IEEE), Norfolk, Virginia, USA, ORCID: https://orcid.org/0000-0002-3263-5217, e-mail: LXu@odu.edu

Zhanna V. Pisarenko, Dr. Sci. (Econ.), Assistant Professor, Saint-Petersburg State University, Economic Faculty, Department of Risk Management and Insurance, Saint-Petersburg, Russia, ORCID: https://orcid.org/0000-0002-9082-2897, e-mail: z.pisarenko@spbu.ru

Cahn T. Nguyen, Dr. of Economics, Professor, Leading Researcher at the Institute of European Studies, Vietnam Academy of Social Sciences, Hanoi, Vietnam, ORCID: https://orcid.org/0000-0001-8709-2283, e-mail: okabc007@gmail.com

Svetlana R. Muminova, Cand. Sci. (Eng.), Chief for foreign relations, Center for New Technologies "Nanostroitel'stvo", Korolev, Moscow region, Russia, ORCID: https://orcid.org/0000-0001-5236-607X, e-mail: it.rguts@mail.ru

\section{All authors declare the absence of any competing interests.}

Received: 28.06.2021.

Revised: 02.08.2021.

Accepted: 05.08.2021. 